\title{
Modelagem por Redes Neurais sem Entradas Atrasadas da Caustificação em Indústria de Celulose
}

\author{
Costa, F. O. M. ${ }^{1 *}$; Pinheiro, O. S. ${ }^{2}$; Costa, A. O. S. ${ }^{3}$; Costa Jr, E. F. ${ }^{3}$ \\ 1 Curso de Graduação em Engenharia Química, Universidade Federal do Espírito Santo, Alegre, ES, Brasil. \\ 2 Celulose Nipo-Brasileira S.A., Belo Oriente, MG, Brasil. \\ 3 Pós-Graduação em Engenharia Química e Graduação em Engenharia Química, Departamento de Engenharia Rural, Universidade \\ Federal do Espírito Santo, ES, Brasil
}

* email: olive_felipe@hotmail.com;

\begin{abstract}
Resumo
Uma parte importante do processo Kraft de obtenção de celulose é o ciclo de recuperação, que permite o aproveitamento como combustível da matéria orgânica da madeira (principalmente lignina), separada no processo de cozimento, e também o reaproveitamento dos compostos químicos utilizados no digestor. Dentro deste ciclo, a caustificação desempenha um importante papel, sendo responsável por transformar o licor verde (proveniente da caldeira de recuperação) em licor de cozimento (licor branco). Sendo assim, este trabalho tem por objetivo gerar modelos empíricos, por redes neurais sem o uso de entradas atrasadas, para o sistema de caustificação de uma fábrica de celulose. Mesmo não utilizando entradas atrasadas, o modelo obtido apresentou coeficiente de determinação $\left(R^{2}\right)$ de 0,61 para os dados de validação, enquanto modelos reportados na literatura apresentaram $R^{2}$ igual a 0,42 para os dados de validação.
\end{abstract}

Palavras chaves: Caustificação, Processo Kraft, Modelagem por redes neurais.

\section{Abstract}

An important part of the Kraft process is the recovery cycle which enables the reuse the chemicals used in the digester and the use of the organic matter from wood (mainly lignin separated in the cooking process) as fuel. Causticizing system has an important role in this cycle since it is responsible for turning green liquor (from the recovery boiler) into cooking liquor (white liquor). Thus, this work aims to generate empirical models for the causticizing system of a pulp mill based on neural networks without late inputs. Even without using late inputs, the model obtained shows an coefficient of determination $\left(R^{2}\right)$ of 0.61 for validation data, while models reported in literature showed $R^{2}$ equal to 0.42 for validation data.

Keywords: Causticizing, Kraft process, modeling using neural networks.

\section{Introdução}

\subsection{O processo Kraft e a caustificação}

O processo Kraft de obtenção de celulose tem por finalidade separar a lignina da celulose e da hemicelulose presentes na madeira, evitando ao máximo a degradação das fibras. O cozimento da madeira no digestor, com o licor branco de cozimento, gera a pasta celulósica a ser branqueada e um subproduto chamado de licor preto. Este licor é rico em lignina e em compostos químicos, produzidos na digestão, a partir dos reagentes químicos do licor branco, a saber, hidróxido de sódio $(\mathrm{NaOH})$ e sulfeto de sódio $\left(\mathrm{Na}_{2} \mathrm{~S}\right)$. A recuperação desses produtos químicos e o aproveitamento da matéria orgânica do licor preto como combustível são de vital importância para a indústria de celulose [1].

O ciclo de recuperação Kraft emprega vários equipamentos, sendo a caustificação a última parte deste ciclo. Na caustificação é formado o licor branco de cozimento por meio da reação da cal, proveniente do 
forno de cal, com uma solução (licor verde) formada pela diluição dos sais fundidos, provenientes da caldeira de recuperação [1]. O sistema de caustificação é composto por uma série de reatores, sendo que a cal adicionada no primeiro deles sofre uma reação de hidratação. A cal hidratada $\left(\mathrm{Ca}(\mathrm{OH})_{2}\right)$ reage com o carbonato de sódio $\left(\mathrm{Na}_{2} \mathrm{CO}_{3}\right)$ do licor verde, recuperando o hidróxido de sódio $(\mathrm{NaOH})$ e produzindo como subproduto 0 carbonato de cálcio $\left(\mathrm{CaCO}_{3}\right)$, que é utilizado no forno de cal [2].

\subsection{Conceito de redes neurais}

Pode-se definir uma rede neural artificial (RNA) como um circuito com uma grande quantidade de unidades de processamento inspiradas no sistema neural [3].

Outra definição análoga à que foi apresentada, é que uma RNA é um sistema massivamente paralelo e distribuído, composto por unidades de processamento que possuem uma capacidade natural de armazenar e utilizar conhecimento [3].

Segundo Cardon \& Muller [4], podem-se distinguir pelo menos dois componentes físicos nas redes neurais, conexões e elementos de processamento e, que a combinação desses dois componentes cria uma RNA. Há também outros componentes, não físicos, das redes neurais: padrões e funções.

Padrões são dados de entrada da rede. Eles são uma codificação que corresponde a determinada modelagem da realidade de uma aplicação definida para a RNA. Funções são modelos matemáticos usados no treinamento e reconhecimento de padrões. Conexões, elementos de processamento, padrões e funções são os componentes básicos de qualquer RNA [4].

\subsection{Objetivo}

Este trabalho tem por finalidade gerar modelos matemáticos empíricos, com base em redes neurais sem entradas atrasadas, para o sistema de Caustificação de uma fábrica de Celulose, com o intuito de predizer a eficiência de Caustificação pós caustificador, EC.

Ressalta-se que, em trabalhos prévios da literatura para este sistema, só foi possível a obtenção de modelos satisfatórios empregando-se entradas atrasadas [5].

\section{Materiais e Métodos}

Todos os dados empregados na geração dos modelos foram obtidos de uma indústria nacional de celulose. Para gerar os modelos foram utilizadas como variáveis independentes (Variáveis de entrada) a vazão de licor, a dosagem de cal, a porcentagem de cal útil, a quantidade de $\mathrm{Na}_{2} \mathrm{CO}_{3}$ e $\mathrm{NaOH}$ no licor verde, além das temperaturas de entrada e saída do extintor. Como variável dependente (Variável de saída) foi usada a eficiência de caustificação pós caustificador, EC. Os modelos foram gerados utilizando-se o programa STATISTICA.

\section{Resultados e Discussões}

O conjunto de dados fornecido pela empresa se constituía de 4321 dados operacionais, que apresentavam um desvio padrão para a variável a ser predita, EC, igual a 2,194\%. Como ponto de partida, foram gerados modelos cujos dados utilizados para geralos não passaram por nenhum tipo de análise. Do conjunto de dados operacionais, 2161 dados foram empregados no treinamento das redes, 1080 para teste e 1080 para a seleção das melhores redes. Os resultados numéricos estatísticos dos modelos são apresentados na Tabela 1.

Tabela 1- Resultado estatístico dos modelos (Para todos os dados).

\begin{tabular}{cccccc}
\hline Modelo: & 1 & 2 & 3 & 4 & 5 \\
\hline Média dos erros & 0,0114 & $-0,0066$ & 0,0713 & 0,0293 & 0,0302 \\
\hline $\begin{array}{c}\text { Desvio padrão } \\
\text { dos erros }\end{array}$ & 1,6334 & 1,4726 & 2,0585 & 1,8770 & 1,8056 \\
\hline Correlação (R) & 0,6676 & 0,7416 & 0,3471 & 0,5180 & 0,5679 \\
\hline
\end{tabular}


Pode-se observar nesta Tabela 1 que o melhor modelo é o modelo 2 , sendo os resultados gráficos, para todos os dados, deste modelo apresentados na Figura 1.

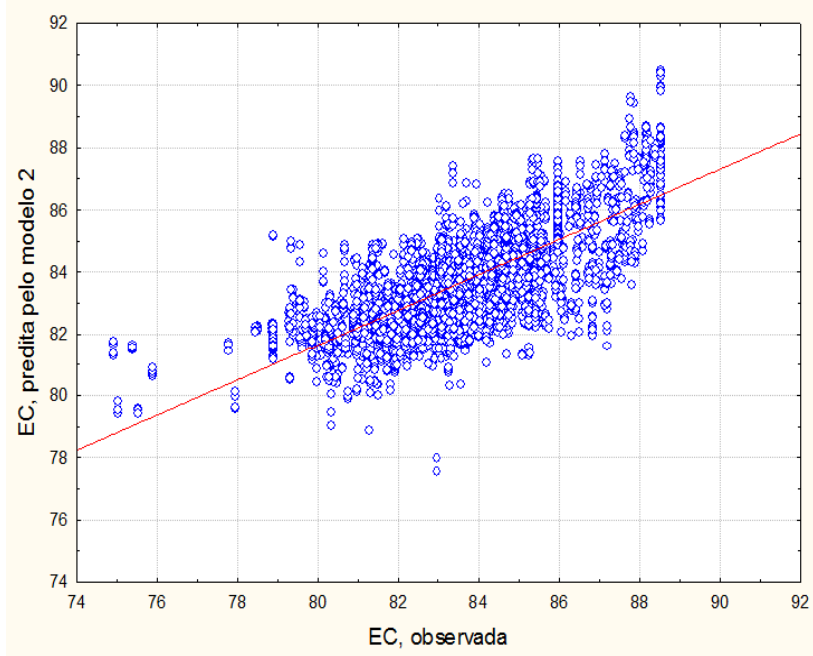

Figura 1- EC observada vs EC predita, modelo sem tratamento dos dados.

Após essa primeira análise, foi feita uma análise dos dados a serem empregados no desenvolvimento das redes. Nesta análise, foram construídos os histogramas de todas as variáveis do problema para que se fossem descartados dados que correspondessem a paradas do processo ou dados que estivessem muito fora da faixa operacional normal dos caustificadores. A Figura 2 apresenta o histograma para a vazão de licor.

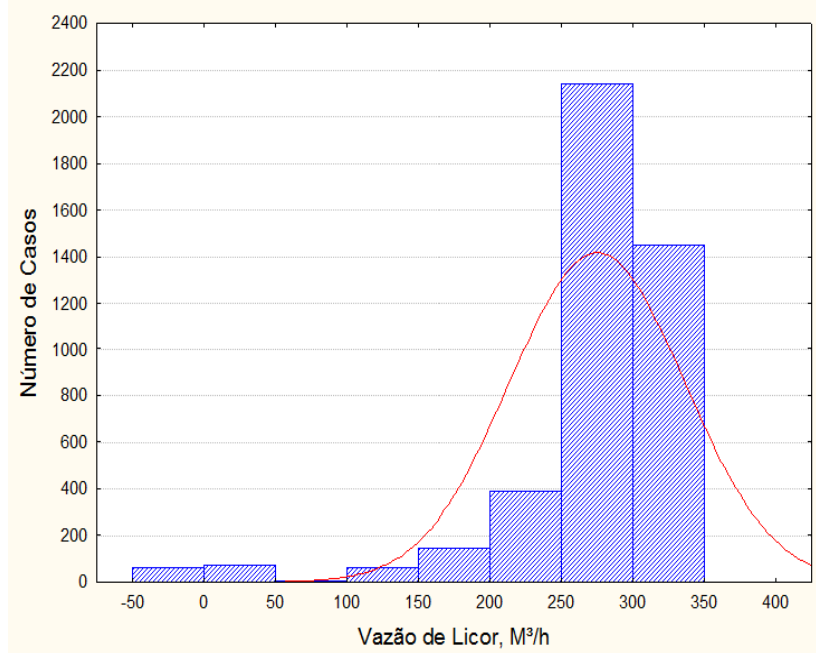

Figura 2- Distribuição da vazão de licor.

Verifica-se nesta Figura 2 que há valores de vazão que não têm significado físico (valores negativos) ou valores de vazão nula (que indicam a parada do equipamento). Mais além, observou-se que para baixos valores desta vazão, o número de dados disponíveis é muito baixo. Desta forma, foram eliminados os dados com valores desta variável inferior a $120 \mathrm{~m}^{3} / \mathrm{h}$ (ponto de corte). Este ponto de corte também definido para as demais variáveis, a saber: $70 \mathrm{Kg} / \mathrm{m}^{3}$, para a variável dosagem de cal, $81 \%$ para a porcentagem de cal útil, $75 \mathrm{Kg} / \mathrm{m}^{3}$ para a quantidade de $\mathrm{Na}_{2} \mathrm{CO}_{3}$ no licor verde, 65으 para a temperatura de entrada no extintor, $92^{\circ} \mathrm{C}$ para a temperatura de saída do extintor e, por fim, o ponto de corte para a eficiência de caustificação foi de $74 \%$. A Figura 3 apresenta o histograma da vazão de licor após o corte.

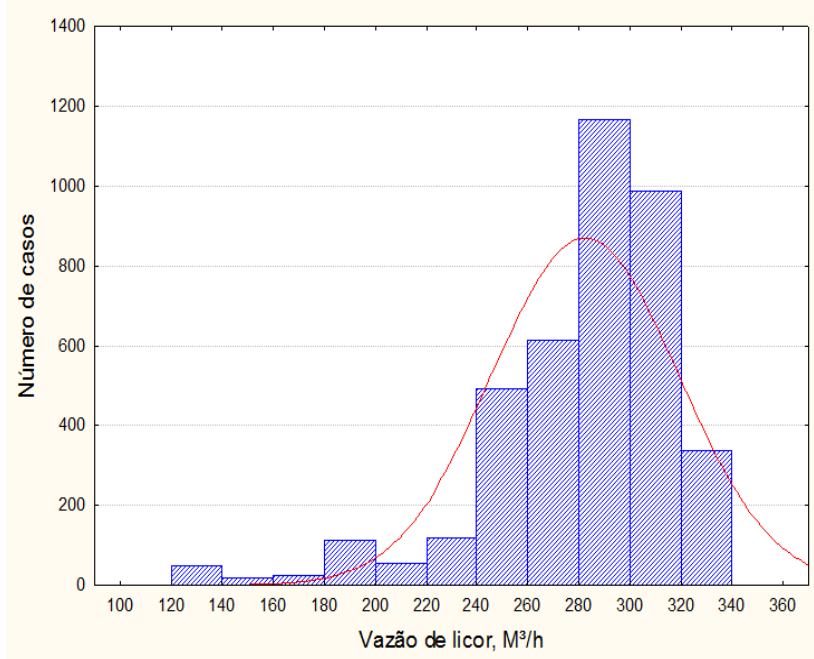

Figura 3- Distribuição da vazão de licor depois do corte dos dados

Após os cortes restaram 3971 pontos operacionais, sendo que 1987 foram usados para treino das redes, 992 para seleção e 992 para teste. Os resultados dos novos modelos gerados são apresentados nas Tabelas 2 e 3.

Tabela 2- Resultados estatísticos no treinamento das redes após o pré-tratamento dos dados.

\begin{tabular}{cccccc}
\hline Modelo: & 6 & 7 & 8 & 9 & 10 \\
\hline Média dos erros & 0,0000 & 0,0000 & 0,0000 & 0,0008 & 0,0019 \\
\hline $\begin{array}{c}\text { Desvio padrão } \\
\text { dos erros }\end{array}$ & 1,2065 & 1,9116 & 1,9425 & 1,9068 & 1,7641 \\
\hline Correlação (R) & 0,8365 & 0,4961 & 0,4706 & 0,4999 & 0,5991 \\
\hline
\end{tabular}


Tabela 3- Resultados estatísticos na validação das redes após o pré-tratamento dos dados.

\begin{tabular}{lccccc}
\hline \multicolumn{1}{c}{ Modelo: } & 6 & 7 & 8 & 9 & 10 \\
\hline Média dos erros & $-0,0656$ & 0,0131 & $-0,0146$ & $-0,0409$ & $-0,0371$ \\
\hline $\begin{array}{l}\text { Desvio padrão } \\
\text { dos erros }\end{array}$ & 1,3320 & 1,8708 & 1,8663 & 1,8234 & 1,7959 \\
\hline Correlação (R) & 0,7838 & 0,4855 & 0,4838 & 0,5168 & 0,5411 \\
\hline
\end{tabular}

Observa-se que, dentre os novos modelos gerados, o que apresenta 0 melhor desempenho, tanto no treinamento quanto na validação, é o modelo 6. A representação gráfica dos resultados, na validação, deste modelo, é apresentada na Figura 4

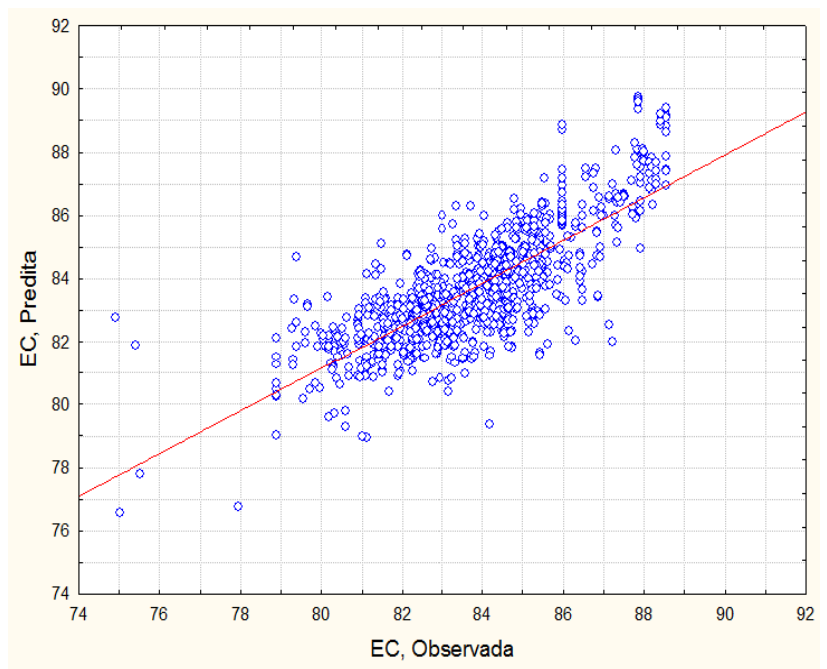

Figura 4- EC predita x EC observada para o modelo 6

\section{Conclusão}

Os dados industriais empregados na realização deste trabalho não foram coletados com o intuito específico de gerar modelos, mas sim de acompanhar a rotina operacional da fábrica. Ressalta-se que no banco de dados da empresa as variáveis são armazenadas considerando-se uma "banda morta", ou seja, só são registrados novos valores se a diferença entre a nova medida e a armazenada no banco de dados for superior a um valor previamente especificado ("banda morta"). Este fato faz com que não se possa esperar um ajuste muito perfeito do modelo aos dados experimentais. Outro desafio deste trabalho a proposta de não se empregar entradas atrasadas na construção do modelo. Neste contexto, pode-se concluir que o modelo 6 , desenvolvido no presente trabalho consiste num avanço, possibilitou um coeficiente de correlação (R) para os dados de validação de 0,7838 , ou seja um coeficiente de determinação $\left(R^{2}\right)$ de 0,6143 contra um valor de $\mathrm{R}^{2}=0,4208$ reportado em trabalho da literatura para modelos do mesmo sistema, também sem entradas atrasadas.

\section{Agradecimentos}

Os autores agradecem ao CNPq pela bolsa de IC e de produtividade DTI e à FAPES pela bolsa pesquisador capixaba.

\section{Referências bibliográficas}

[1] FIGUEIRÊDO, Leonardo Soares. Modelagem Matemática do Estado Estacionário de um Real Sistema de Caustificação em uma Fábrica de Celulose. 71 f.

Dissertação (Mestrado em Engenharia Industrial) - Centro Universitário do Leste de Minas Gerais, Coronel

Fabriciano, 2009.

[2] MENESES, Rodrigo F. de. Modelagem do sistema de recuperação do licor de cozimento na produção de celulose. 2005. 23 p.

[3] CASTRO, Leandro N. de; VON ZUBEN, Fernando J. Redes Neurais Artificiais. Disponível em:

$<\mathrm{ftp}$ ://ftp.dca.fee.unicamp.br/pub/docs/vonzuben/ia006_0 3/topico5_03.pdf>. Acesso em 20 de Fevereiro de 2015.

[4] CARDON, André; MULLER, Daniel N. Introdução às Redes Neurais Artifíciais. Porto Alegre, 1994. Disponível em:

$<$ <ttp://www.inf.ufrgs.br/ danielnm/docs/intro_rna.pdf>. Acesso em 20 de Fevereiro de 2015.

[5] PEREIRA, M. C. V. et al. Modelagem por redes neurais de um reator de pré-branqueamento. P. 13711380, 2012. 